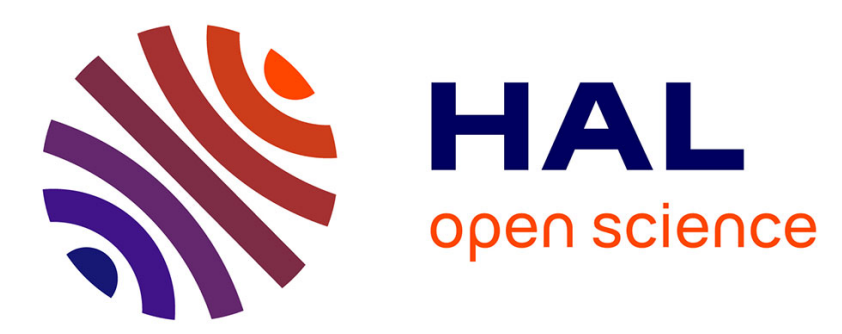

\title{
Surface composition and micromasking effect during the etching of amorphous Ge-Sb-Se thin films in SF6 and SF6/Ar plasmas
}

Thibaut Meyer, Aurelie Girard, Guillaume Le Dain, Ahmed Rhallabi, Emeline Baudet, Virginie Nazabal, Petr Němec, Christophe Cardinaud

\section{To cite this version:}

Thibaut Meyer, Aurelie Girard, Guillaume Le Dain, Ahmed Rhallabi, Emeline Baudet, et al.. Surface composition and micromasking effect during the etching of amorphous Ge-Sb-Se thin films in SF6 and SF6/Ar plasmas. Applied Surface Science, 2021, 549, pp.149192. 10.1016/j.apsusc.2021.149192 . hal-03194243

\section{HAL Id: hal-03194243 \\ https://hal.science/hal-03194243}

Submitted on 13 Apr 2021

HAL is a multi-disciplinary open access archive for the deposit and dissemination of scientific research documents, whether they are published or not. The documents may come from teaching and research institutions in France or abroad, or from public or private research centers.
L'archive ouverte pluridisciplinaire HAL, est destinée au dépôt et à la diffusion de documents scientifiques de niveau recherche, publiés ou non, émanant des établissements d'enseignement et de recherche français ou étrangers, des laboratoires publics ou privés. 


\title{
Surface composition and micromasking effect during the etching of amorphous Ge-Sb-Se thin films in $\mathrm{SF}_{6}$ and $\mathrm{SF}_{6} /$ Ar plasmas
}

\author{
T. Meyer ${ }^{\mathrm{a}}$, A. Girard ${ }^{\mathrm{a}}$, G. Le Dain ${ }^{\mathrm{a}}$, A. Rhallabia ${ }^{\mathrm{a}}$, E. Baudet ${ }^{\mathrm{b}}$, V. Nazabal ${ }^{\mathrm{b}}$, P. Němec ${ }^{\mathrm{c}}$, C. \\ Cardinaud ${ }^{\mathrm{a}, *}$ \\ ${ }^{a}$ Université de Nantes, CNRS, Institut des Matériaux Jean Rouxel, IMN, F-44000 Nantes, France \\ ${ }^{b}$ Univ Rennes, CNRS, ISCR (Institut des Sciences Chimiques de Rennes) - UMR 6226, F-35000 Rennes, France \\ ${ }^{c}$ Department of Graphic Arts and Photophysics, Faculty of Chemical Technology, University of Pardubice, Studentská \\ 573, 53210 Pardubice, Czech Republic
}

\begin{abstract}
A functional waveguide for photonic applications must fulfil some specific requirements in terms of dimension, shape, etch rate and roughness. In this study, Ge-Sb-Se thin films were etched using an Inductively Coupled Plasma reactor via fluorine-based chemistry. In a $\mathrm{SF}_{6}$ plasma, etch rate and roughness highlight a micro masking effect which originates from the formation of $\mathrm{SbF}_{3},(\mathrm{Se})-\mathrm{Sb}-\mathrm{F}_{x}$ and $(\mathrm{Sb})-\mathrm{Se}-\mathrm{F}$ environments. The latter have been identified with in situ XPS. Systematically, a $\mathrm{SF}_{6}$ plasma is associated with a quasi-isotropic profile and a rough surface. In a $\mathrm{SF}_{6} / \mathrm{Ar}$ plasma, the impact of pressure and the argon content has been investigated. The addition of argon affects directly the fluorine atom flux and the argon atom flux which were calculated using a global model. It was found that there is a strong coherence between the fluorine atom flux, the proportion of fluorine at the surface and the RMS roughness. A synergistic effect, between ion bombardment and reactive neutral species, is observed when varying both parameters. Surface is free of fluorinated products for a high percentage of argon (95\%) and low-pressures $(<4 \mathrm{mT}$ Torr). A smooth surface and a quasi-vertical profile were achieved in a $\mathrm{SF}_{6} / \mathrm{Ar}$ with a gas mixture ratio 5/95 and at a pressure of 1.5 mTorr.
\end{abstract}

Keywords: Ge-Sb-Se, Etching, ICP, $\mathrm{SF}_{6}$, Micromasking

\footnotetext{
* Corresponding author

Email address: christophe. cardinaud@cnrs-imn.fr (C. Cardinaud)
} 


\section{Introduction}

Chalcogenide glasses (ChGs) contain at least one chalcogen element ( $\mathrm{S}, \mathrm{Se}, \mathrm{Te})$ and one or more elements from the $14^{\text {th }}$ (typically $\mathrm{Ge}$ ) and/or $15^{\text {th }}(\mathrm{As}, \mathrm{Sb}$ ) columns of the periodic table. These materials are known for their good optical transmittance in the infrared region and their high linear and nonlinear refractive index [1]. Consequently, ChGs such as As-S [2], Ge-Sb-S [3], Ge-Sb-Se [4] or Ge-As-Se [5] are used as waveguides dedicated for infrared spectroscopy, all-optical signal processing etc. However, the use of the arsenic based-ChGs could be an issue for environmental applications because of its elemental form toxicity. A way to get around that is to substitute antimony to arsenic.

Many efforts are invested in the manufacturing of the Ge-Sb-Se waveguides with a promising application in monitoring of molecule concentrations, exploiting the molecule signatures in the mid-infrared region [6-8]. Nevertheless, the performance of a waveguide relies on its optical losses.

Key parameters as the composition, the dimension and the sidewall roughness of the waveguide affect its optical properties [9]. Therefore, there is a vast room of improvement to limit the optical losses by means of the deposition method and the patterning process. Plasma etching is a well-known technique providing anisotropic profile and smooth surfaces. Etching of chalcogenide thin films has been systematically studied using halogen-based plasmas such as $\mathrm{CF}_{4}[10,11], \mathrm{CHF}_{3}[12], \mathrm{Cl}_{2}$ [13] etc. The etching of $\mathrm{Ge}_{20} \mathrm{Sb}_{15} \mathrm{Se}_{65}$ and $\mathrm{Ge}_{28.1} \mathrm{Sb}_{6.3} \mathrm{Se}_{65.6}$ has been performed using $\mathrm{CHF}_{3}$ and $\mathrm{CF}_{4}$ plasmas [14-16]. An etch rate of $1.4 \mu \mathrm{m} / \mathrm{min}$ and a sidewall angle of $85^{\circ}$ have been reported during the etching of $\mathrm{Ge}_{20} \mathrm{Sb}_{5} \mathrm{Se}_{75}$ in $\mathrm{CHF}_{3}$ [17]. To the best of our knowledge, the interaction between fluorine atoms and the Ge-Sb-Se system was not investigated in $\mathrm{SF}_{6}$ plasma yet. Furthermore, using a different chemistry extends the fundamental knowledge of ChGs, and we can discuss about the viability for industrial application.

In this paper, we studied the etching of amorphous Ge-Sb-Se thin films using $\mathrm{SF}_{6}$ and $\mathrm{SF}_{6} / \mathrm{Ar}$ plasmas. The former chemistry, though inadequate, brings out the limitation of fluorine-based plasmas, and the latter introduces an unused and effective way to achieve a quasi-vertical sidewall profile. The surface composition, the etch rate and the roughness are investigated when the pressure and the argon content are varied. 


\section{Methods}

$\mathrm{Ge}_{19} \mathrm{Sb}_{21} \mathrm{Se}_{60}$ thin films with a thickness of $\sim 1.5 \mu \mathrm{m}$ were deposited by pulsed laser deposition, by ablating a $\mathrm{Ge}_{19.5} \mathrm{Sb}_{17.8} \mathrm{Se}_{62.7}$ bulk target with a $\mathrm{KrF}$ excimer laser (Compex 102, Lambda Physik) [18]. The composition of the thin films $( \pm 1 \%)$ and the bulk target $( \pm 0.5 \%)$ were determined by Energy Dispersive X-ray Spectroscopy (JSM 6400-OXFORD Link INCA). In addition, vitreous Se (4N pellet; Codex International), germanium (5N 4" wafer; Goodfellow), $\mathrm{Sb}\left(1 * 2 \mathrm{~cm}\right.$ ingot; HiChem SPOL S.R.O) and $\mathrm{Sb}_{2} \mathrm{Se}_{3}(5 \mathrm{~cm}$ diameter target; HiChem SPOL S.R.O) were used. $\mathrm{Sb}$ and $\mathrm{Sb}_{2} \mathrm{Se}_{3}$ powders were prepared from the related bulk materials. All thin film samples were kept under inert atmosphere until etching or analysis in order to avoid oxidation and surface contamination.

Etching was performed in an Inductively Coupled Plasma reactor (ICP). The plasma source is located in the upper part of the reactor and consisted of an alumina tube of $18 \mathrm{~cm}$ in diameter and $26 \mathrm{~cm}$ in height, with an external loop antenna operating at $13.56 \mathrm{MHz}$. The diffusion chamber is $35 \mathrm{~cm}$ in diameter and $47 \mathrm{~cm}$ in height. Samples are placed at the centre of the reactor on a $100 \mathrm{~mm}$ substrate. The latter is mechanically clamped to the substrate holder and located $17 \mathrm{~cm}$ below the bottom of the alumina tube. The substrate temperature was maintained at $20^{\circ} \mathrm{C}$ thanks to a He cooling system. Mass flow controllers adjust the process gas flow rate inside the diffusion chamber. Before the etching sequence, the chamber conditioning consists in a $\mathrm{C}_{4} \mathrm{~F}_{8}$ plasma for 30 minutes at $10 \mathrm{~m}$ Torr and $400 \mathrm{~W}$ to deposit a teflon-like layer on the reactor wall. Between processes, a cleaning procedure using $\mathrm{H}_{2} / \mathrm{Ar}$ plasma removes the etching products $\left(\mathrm{GeF}_{x}, \mathrm{SbF}_{x}\right.$ and $\mathrm{SeF}_{x}$ ) from the reactor wall and the substrate holder.

For patterned samples, a standard photolithography process was applied using a S1818 photoresist with a thickness of $\sim 1.5 \mu \mathrm{m}$. Etch depths were measured using a surface profilometer (DEKTAK 8 VEECO). Atomic force microscopy (NanoWizard 3 JPK Instruments) was performed to measure the RMS roughness with a scanning size of $3 \times 3 \mu \mathrm{m}^{2}$ on blank samples. The surface morphology was examined using a scanning electron microscope (SEM, JEOL JSM 7600F).

The composition of the surface and chemical bonding were examined by in situ X-Ray Photoelectron Spectroscopy (XPS) on blank samples. Samples are transferred under ultra-high vacuum from the etching chamber to the analysis chamber, via an intermediate buffer chamber. This procedure avoids any post etching contamination of the sample surface and preserves the XPS cham- 
ber from contamination from the etching vessel. The device is composed of a monochromatic $\mathrm{Al} \mathrm{K} \alpha$ X-ray source ( $\mathrm{h} v=1486.6 \mathrm{eV}$, SPECS XR $50 \mathrm{M}$ and FOCUS 500) and a hemispherical analyser (PHOIBOS HR 150). Wide spectra were recorded with a pass energy of $30 \mathrm{eV}$ with an energy step of $1 \mathrm{eV}$. XPS narrow spectra were obtained using a pass energy of $14 \mathrm{eV}$ with an energy step of $0.1 \mathrm{eV}$. Sample charging was neutralized with an electron flood gun. Data were processed using CASA-XPS software where Ge $2 \mathrm{p}_{3 / 2}$, F 1s, Sb 3d and Se $3 \mathrm{~d}$ core levels were decomposed using a Shirley background [19] and a Lorentzian function convoluted with a Gaussian. Sensitivity factors were retrieved from $\mathrm{GeSe}_{2}$ and $\mathrm{Sb}_{2} \mathrm{Se}_{3}$ powders and $\mathrm{Ge}_{19} \mathrm{Sb}_{21} \mathrm{Se}_{60}$ thin film. To probe variation of the relative atomic proportions of $\mathrm{Ge}, \mathrm{Sb}$ and $\mathrm{Se}$ within the analysed depth and versus the etching conditions, atomic percentages were calculated using the Ge $2 \mathrm{p}_{3 / 2}$, $\mathrm{Sb} 3 \mathrm{~d}$ and $\mathrm{Se} 3 \mathrm{~d}$ core levels without taking into account the F 1s area. However, the relative area of the F 1s region was calculated by taking into account all investigated core levels. It should be pointed out that the inelastic mean free path of Ge 2 $p_{3 / 2}$, Sb 3d and Se $3 \mathrm{~d}$ photoelectrons are different. Thus, the atomic percentages are calculated over different analysed depths. Energy calibration of $\mathrm{Ge}, \mathrm{Sb}$ and Se XPS spectra was performed using the Ge-Ge (Binding Energy, BE $=29.0 \mathrm{eV}), \mathrm{Sb}-\mathrm{Sb}(\mathrm{BE}=528.0 \mathrm{eV})$ and $\mathrm{Se}-\mathrm{Se}(\mathrm{BE}=55.3 \mathrm{eV})$ chemical states. $\mathrm{Sb}_{2} \mathrm{Se}_{3}$ and Ge$\mathrm{Sb}-\mathrm{Se} \mathrm{XPS}$ spectra were calibrated using the $\left[\mathrm{SbSe}_{3 / 2}\right]$ motif $(\mathrm{BE}=529.0 \mathrm{eV})$ as the reference value. The uncertainty of the binding energy values is $\pm 0.2 \mathrm{eV}$. The $d_{5 / 2}$ and $d_{3 / 2}$ components of individual doublets were constrained with an equal Full Width Half Maximum. Moreover, the peak separation and the peak area ratio were set at $9.35 \mathrm{eV}-0.667$ for $\mathrm{Sb} 3 \mathrm{~d}$ and $0.85 \mathrm{eV}-0.72$ for Se 3d. The mentioned fit parameters were retrieved from nonetched $\mathrm{Ge}, \mathrm{Sb}$ and $\mathrm{Se}$ samples.

A kinetic model was used to provide a basic understanding of the plasma chemistry. It was developed for a low-pressure, $\mathrm{RF}\left(13.56 \mathrm{MHz}\right.$ ), ICP $\mathrm{SF}_{6} / \mathrm{Ar}$ mixture. The comparison between modeling and experimental data can be found elsewhere [20]. The model takes into account kinetic reactions related to $\mathrm{SF}_{x}, \mathrm{~F}$ and $\mathrm{Ar}$ as the attachment, excitation, dissociation and ionization by electronic impact. Rate coefficients are calculated from cross-section data considering a Maxwellian electron energy distribution function [21-24]. Rate coefficients for neutral recombination and ion recombination reactions are included in the model [25, 26]. Diffusion of reactive neutrals and positive ions is considered [27]. Onto surface, adsorption and desorption can occur, regarding the atom or molecule concerned. On the basis of experimental data made in $\mathrm{SF}_{6}$ [20], the sticking coefficient was set at 0.02 for $\mathrm{SF}_{x}(x=0,1,3,5)$ and $\mathrm{F}$ species. The model solves 
plasma physics equations system: the mass-balance equations, the charge neutrality equation and the power balance equation. Reaction rate coefficients were injected in the mass-balance equations to determine the density of each species considered. Charge neutrality equation and power balance equation evaluated the electron density and the electronic temperature, respectively. Input parameters are the dimension of the simplified reactor (cylindrical geometry), the source power, the pressure, the total flow rate and gas temperature. The latter was assumed equal to the temperature of the wall $(300 \mathrm{~K})$. The model provides information about the plasma parameters and the particles characteristics (density, flux). In the present paper, the model was used for the $\mathrm{SF}_{6} / \mathrm{Ar}$ chemistry to calculate the radical and ion fluxes.

\section{Results and discussion}

\subsection{Etching in pure $S F_{6}$}

To understand the etching mechanisms, it is crucial to get information about the volatility of the etching products. Without pertinent data on the species, only a minimalist approach can be made with the use of the boiling temperatures as for $\mathrm{GeF}_{2}$ and $\mathrm{GeF}_{4}$. In other cases, the vapour pressures can be calculated from Antoine coefficients as for $\mathrm{SbF}_{3}, \mathrm{SbF}_{5}, \mathrm{SeF}_{2}$ and $\mathrm{SeF}_{4}$ [28-30]. As displayed in Fig. 1, it is expected that the $\mathrm{SbF}_{5}, \mathrm{SeF}_{6}, \mathrm{SeF}_{4}, \mathrm{GeF}_{4}$ and $\mathrm{GeF}_{2}$ species are volatile and the $\mathrm{SbF}_{3}$ molecule is nonvolatile, and so, the latter should be detected at the surface. The vapour pressures data are reliable for the etching of pure elements. For binary or ternary materials, mixed nonvolatile products may occur depending on the structure of the etched material and the plasma chemistry.

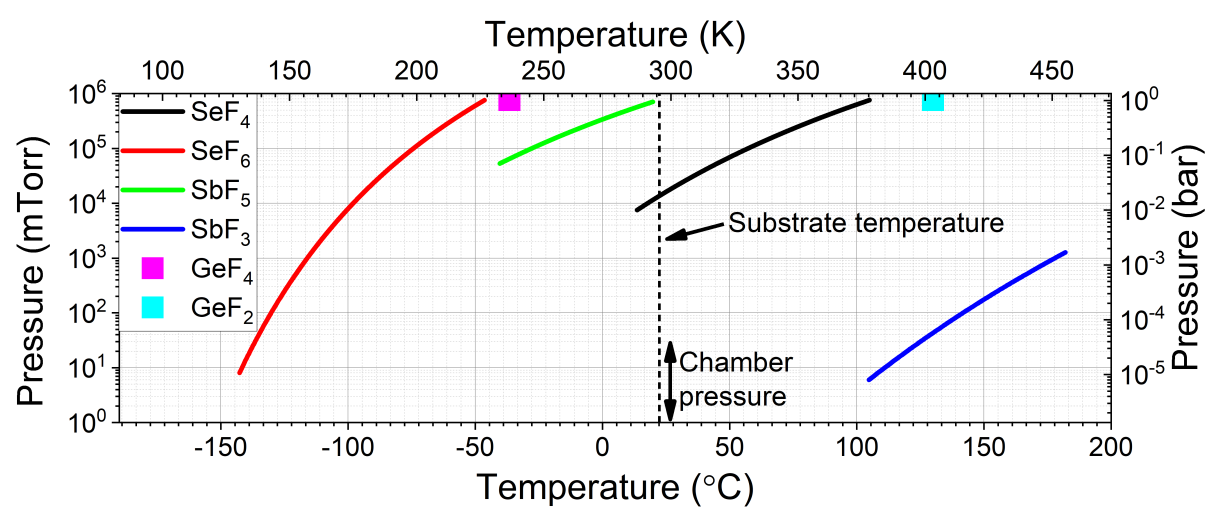

Fig. 1: Vapour pressures and boiling temperatures of fluorinated compounds [28-30]. 


\subsubsection{In situ XPS analysis}

Wide XPS spectra are presented in Fig. 2 after etching. Literature concerning the XPS analysis of Ge-Sb-Se system shows that $\mathrm{SbSe}_{3 / 2}$ pyramids and $\mathrm{GeSe}_{4 / 2}$ tetrahedra are the dominant motifs $[18,31,32]$. The quantification of relative atomic percentages shows a Ge-depletion considering $\mathrm{Ge}, \mathrm{Sb}$ and $\mathrm{Se}$ elements. In the absence of bias, a weak $\mathrm{Al}$ contamination is present at the surface, coming from the alumina tube. In this specific case, the $\mathrm{Al} 2 \mathrm{~s}$ and $\mathrm{Al} 2 \mathrm{p}$ are distinct from the Ge $3 p$ core level $(\mathrm{BE}=123 \mathrm{eV})$ and from the Se $3 \mathrm{~d}$ energy loss $(\mathrm{BE} \approx 70 / 80 \mathrm{eV})$, respectively. In addition, the $\mathrm{F} 1 \mathrm{~s}$ area represents $55 \%$ of the summed areas $\left(\mathrm{Ge} 2 \mathrm{p}_{3 / 2}+\mathrm{F} 1 \mathrm{~s}+\mathrm{Sb}\right.$ $3 d+$ Se $3 d$ ), implying the presence of fluorinated compounds at the surface. Note that sulfur is not detected due to an overlapping of its contributions with the Se $3 \mathrm{~s}$ and $3 p$ core levels. The relative atomic percentage of sulfur at the surface is considered to be negligible (at. $<1 \%$ ) compared to that of Se.

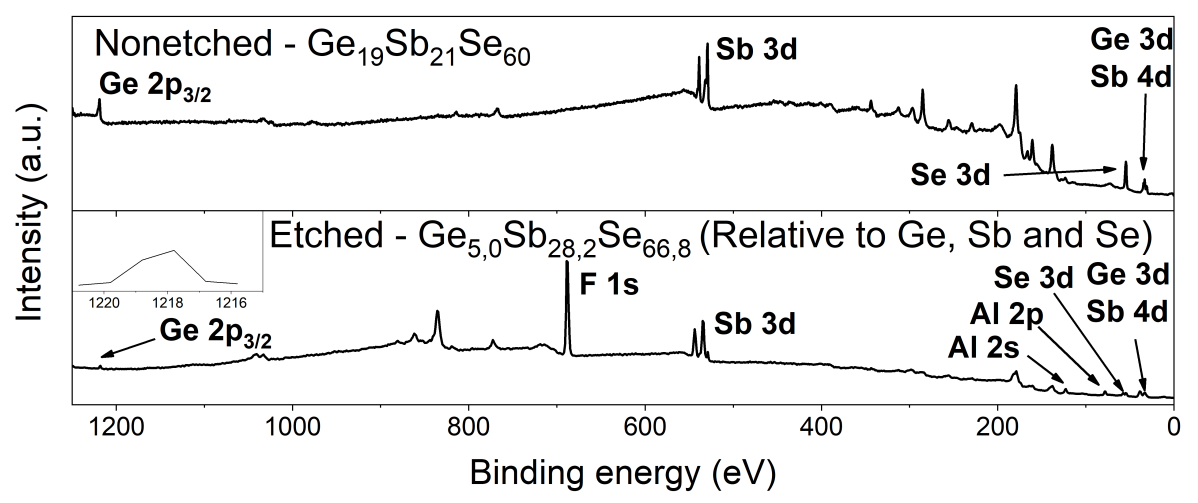

Fig. 2: Wide XPS spectra before and after $\mathrm{SF}_{6}$ etching. (Etching conditions: 10 mTorr, 20 sccm, 700 W and unbiased substrate)

Fig. 3 shows the Ge $2 p_{3 / 2}$ narrow spectra. Surface of the Ge sample was also decomposed and compared to those of the nonetched and etched Ge-Sb-Se thin films. On the Ge surface, the Ge-Ge homopolar bond is located at $1217.1 \mathrm{eV}$. Based on the chemical shift of the others contributions, $(\mathrm{Ge})_{3}-\mathrm{Ge}-\mathrm{F}$ and $(\mathrm{Ge})-\mathrm{Ge}-\mathrm{F}_{3}$ species are positioned at $1217.6 \mathrm{eV}(\mathrm{CS}=0.5 \mathrm{eV})$ and $1218.8 \mathrm{eV}(\mathrm{CS}=1.7 \mathrm{eV})$, respectively. The nonetched $\mathrm{Ge}-\mathrm{Sb}-\mathrm{Se}$ thin film exhibits the Ge$\mathrm{O}$ chemical state, due to the air contamination (untreated), and the $\left[\mathrm{GeSe}_{4 / 2}\right]$ motif located at $1218.6 \mathrm{eV}(\mathrm{CS}=1.5 \mathrm{eV})$. The environment of $\mathrm{Ge}$ atoms is different on the surface of the etched $\mathrm{Ge}-\mathrm{Sb}-\mathrm{Se}$ thin film due to the initial $\left[\mathrm{GeSe}_{4 / 2}\right]$ motif. Thus, the peaks at $1218.4 \mathrm{eV}$ (CS $=1.3$ 
$\mathrm{eV})$ and $1219.6 \mathrm{eV}(\mathrm{CS}=2.5 \mathrm{eV})$ ascribe the $(\mathrm{Se})-\mathrm{Ge}-\mathrm{F}_{x}$ entities. In that case, it is not clear to determine the number of fluorine or selenium atoms bonded to germanium. Starting from the [GeSe $\left.{ }_{4 / 2}\right]$ motif, a negative shift (- $0.2 \mathrm{eV}$ ) implies that $\mathrm{Ge}$ is not necessarily bonded to four atoms. Based on the volatility of the $\mathrm{GeF}_{4}$ species and the lower inelastic mean free path of $\mathrm{Ge}$ $2 \mathrm{p}_{3 / 2}$ photoelectrons compared with those of $\mathrm{Sb} 3 \mathrm{~d}$ and $\mathrm{Se} 3 \mathrm{~d}$ photoelectrons, the observed $\mathrm{Ge}$ depletion is a consequence of an accumulation of fluorinated compounds at the surface.

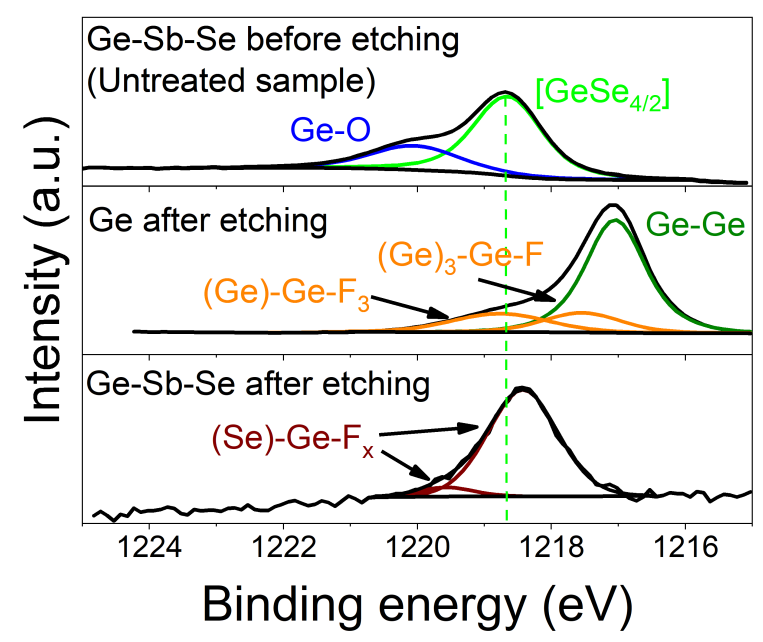

Fig. 3: Ge $2 \mathrm{p}_{3 / 2}$ spectra after $\mathrm{SF}_{6}$ etching. (Etching conditions: $10 \mathrm{mTorr}, 20 \mathrm{sccm}, 700 \mathrm{~W}$ and unbiased substrate)

Fig. 4 shows the $\mathrm{Sb} 3 \mathrm{~d}$ spectra before and after $\mathrm{SF}_{6}$ etching. For comparison purposes, the analysis was also performed on $\mathrm{Sb}$ and $\mathrm{Sb}_{2} \mathrm{Se}_{3}$ powders. On the former, the $\mathrm{Sb}-\mathrm{Sb}$ homopolar bond is positioned at $528.1 \mathrm{eV}$. The doublets at $529.6 \mathrm{eV}(\mathrm{CS}=1.5 \mathrm{eV}), 531.1 \mathrm{eV}(\mathrm{CS}=3.0 \mathrm{eV})$ and $532.1 \mathrm{eV}(\mathrm{CS}=4.0 \mathrm{eV})$ are assigned to the $(\mathrm{Sb})-\mathrm{Sb}-\mathrm{F}_{x}$ species owing to the shift to higher values of binding energy. Important shifts have been reported for $\mathrm{SbF}_{3}(\mathrm{BE}=531.9 \mathrm{eV} ; \mathrm{CS}=3.4$ $\mathrm{eV})$ [33], $\mathrm{SbF}_{4}(\mathrm{BE}=531.0 / 532.0 \mathrm{eV})$ [34], $\mathrm{KSbF}_{5}(\mathrm{BE}=532.7 \mathrm{eV} ; \mathrm{CS}=4.7 \mathrm{eV})$ [35], $\mathrm{CSbF}_{5}$ $(\mathrm{BE}=532.3)$. On the nonetched $\mathrm{Ge}-\mathrm{Sb}-\mathrm{Se}$ sample, the dominant contribution is attributed to the $\left[\mathrm{SbSe}_{3 / 2}\right]$ motif at $529.0 \mathrm{eV}(\mathrm{CS}=0.9 \mathrm{eV})$. The $\mathrm{Sb}-\mathrm{O}$ and $\mathrm{O} 1 \mathrm{~s}$ contributions originate from the air contamination. As displayed on the $\mathrm{Sb}_{2} \mathrm{Se}_{3}$ spectra, the contribution at lower energy (BE $=529.0 \mathrm{eV})$ is assigned to the $\left[\mathrm{SbSe}_{3 / 2}\right]$ motif. The superposition of the selenide component with the (Sb)-Sb- $\mathrm{F}_{x}$ species is not considered because it would imply the detection of the $\mathrm{Sb}-\mathrm{Sb}$ homopolar bond. The adsorption of fluorine on the $\mathrm{Sb}-\mathrm{Se}$ system generates the ( $\mathrm{Se})_{2}-\mathrm{Sb}-\mathrm{F}$ entity at $531.2 \mathrm{eV}(\mathrm{CS}=3.1 \mathrm{eV})$ and the $\mathrm{SbF}_{3}$ species at $532.1 \mathrm{eV}(\mathrm{CS}=4.0 \mathrm{eV})$. 


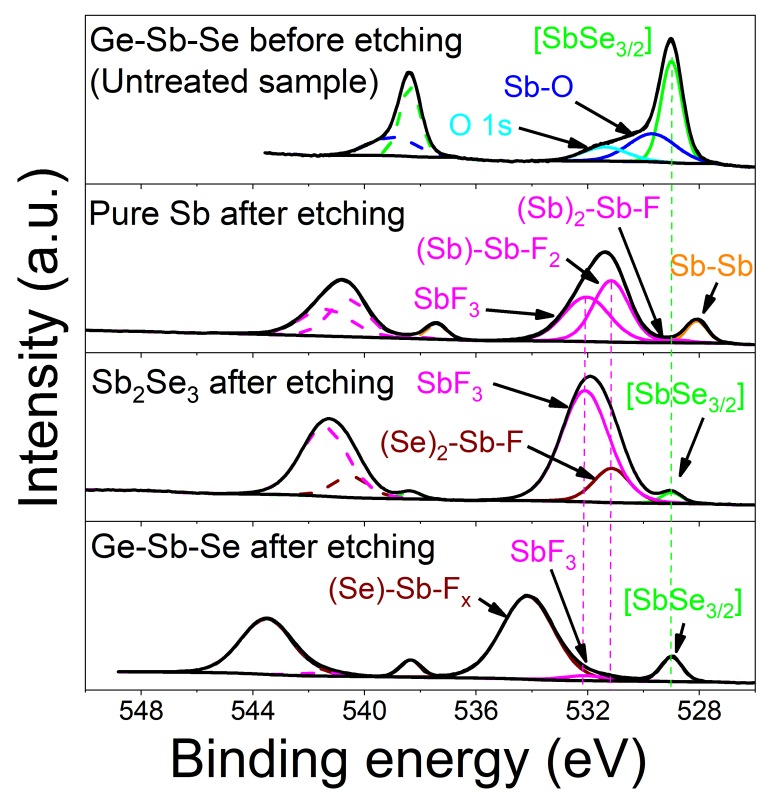

Fig. 4: Sb 3d spectra after $\mathrm{SF}_{6}$ etching. (Etching conditions: 10 mTorr, $20 \mathrm{sccm}, 700 \mathrm{~W}$ and unbiased substrate)

For the etched Ge-Sb-Se, the doublet at $529.0 \mathrm{eV}(\mathrm{CS}=0.9 \mathrm{eV})$ is assigned to the $\left[\mathrm{SbSe}_{3 / 2}\right]$ motif. Two additional doublets are needed to fit the $\mathrm{Sb} 3 \mathrm{~d}$ core level. The first doublet at 532.1 $\mathrm{eV}(\mathrm{CS}=4.0 \mathrm{eV})$ and the second doublet at $534.2(\mathrm{CS}=6.1 \mathrm{eV})$ are attributed to the $\mathrm{SbF}_{3}$ and the mixed (Se)-Sb-F $\mathrm{F}_{x}$ products. Although the latter is well defined, it is not possible to determine the number of fluorine or selenium atoms which are bonded to the antimony atoms. It could be speculated that the latter contribution is a consequence of a Ge depletion because it does not appear on the $\mathrm{Sb}_{2} \mathrm{Se}_{3}$ powder.

Se 3d XPS spectra are presented in Fig. 5. A pure vitreous $\mathrm{Se}$ and a $\mathrm{Sb}_{2} \mathrm{Se}_{3}$ powder provide information about the Se-F and the (Sb)-Se-F species, although the $\mathrm{Sb}_{2} \mathrm{Se}_{3}$ spectrum is not decomposed because of large uncertainty. For the selenium sample, no other contribution than the homopolar Se-Se bond is detected, although two peaks at $55.3 \mathrm{eV}$ and $55.7 \mathrm{eV}$ are needed since vitreous $\mathrm{Se}$ can form $\mathrm{Se}_{8}$ rings and chains [36, 37]. The absence of fluorinated species confirms the volatility of the $\mathrm{SeF}_{4}$ and $\mathrm{SeF}_{6}$ products. Then, the bonding of $\mathrm{Sb}$ to $\mathrm{Se}, \mathrm{Sb}_{2} \mathrm{Se}_{3}$, induces a chemical shift to a lower binding energy since the electronegativity of antimony (2.05) is lower than that of selenium (2.55). The broad contribution from 57 to $61 \mathrm{eV}$ corresponds to the mixed (Sb)-Se-F products which is obviously independent of a Ge depletion. It should be noticed that 
the neighbouring atoms of a Se atoms is different than that of $\mathrm{Sb}$ atoms.

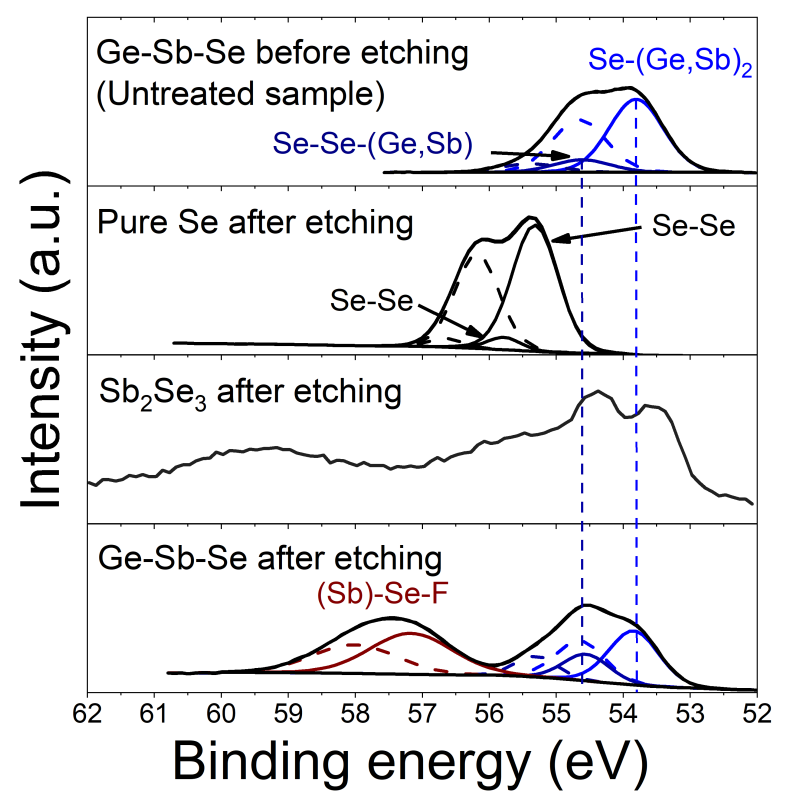

Fig. 5: Se 3d spectra after $\mathrm{SF}_{6}$ etching. (Etching conditions: $10 \mathrm{mTorr}, 20 \mathrm{sccm}, 700 \mathrm{~W}$ and unbiased substrate)

The nonetched Ge-Sb-Se thin film is decomposed with two distinct environments Se-Se- $(\mathrm{Ge}$, $\mathrm{Sb})(\mathrm{BE}=53.8 \mathrm{eV})$ and $\mathrm{Se}-(\mathrm{Ge}, \mathrm{Sb})_{2}(\mathrm{BE}=54.6 \mathrm{eV})$. It has been shown that the $\mathrm{BE}$ values of the two entities depend on the composition of the investigated Ge-Sb-Se material [18, 31, 32, 38]. Turning to the etched Ge-Sb-Se thin film, the large contribution centred at $57.2 \mathrm{eV}$ is assigned to be the $(\mathrm{Sb})-\mathrm{Se}-\mathrm{F}$ environment. As shown by comparing with the pure selenium sample, the doublet cannot be solely the Se-F species because of their volatility. Besides, no energy shift is reported for the $\mathrm{Se}-\mathrm{Se}-(\mathrm{Ge}, \mathrm{Sb})(\mathrm{BE}=53.8 \mathrm{eV})$ and $\mathrm{Se}-(\mathrm{Ge}, \mathrm{Sb})_{2}(\mathrm{BE}=54.6 \mathrm{eV})$ environments

\subsubsection{A micromasking effect}

Table 1 presents the etch rate, the RMS roughness and simulation data regarding the etching conditions. It is expected that the interaction, between fluorine atoms and the elements within the amorphous material, forms nonvolatile products regardless of the conditions. Thus, the process could be apprehended as an outcome between the formation rates of these products, the etching of these products and the etching of the thin film. At lower bias potential (- $7 \mathrm{~V})$, nonvolatile products accumulate at the surface forming a rough surface and reducing the interaction between fluorine atoms and the underlying material. As the bias increases, the energetic ions break the 

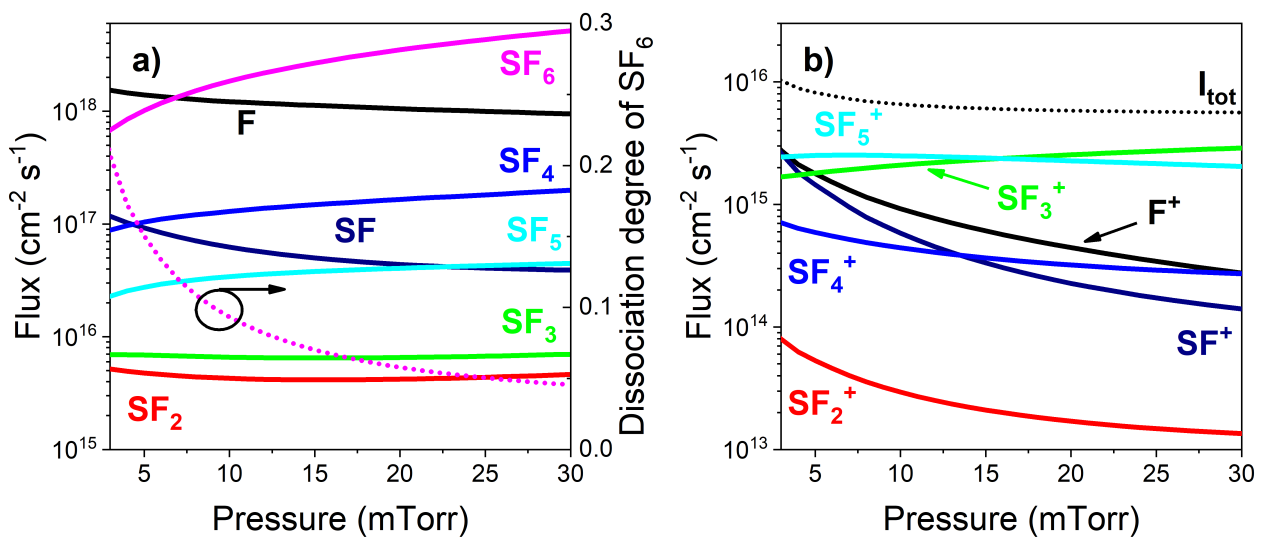

Fig. 6: a) Radical fluxes and b) positive ion fluxes according to the pressure at $1200 \mathrm{~W}$ and $20 \mathrm{sccm}$ (modeling).

Table 1: Etch rate, roughness and simulation data $\left(\Gamma_{F}\right.$ : fluorine atom flux; $\Gamma_{I+}$ : positive ionic flux; $\mathrm{n}_{e}$ : electronic density) according to the plasma conditions with a etch time of 5 minutes and a $\mathrm{SF}_{6}$ flow rate set at $20 \mathrm{sccm}$. The margin error of the etch rate is $\pm 2 \mathrm{~nm} / \mathrm{min}$.

\begin{tabular}{cccccccc}
\hline $\begin{array}{c}\text { Pressure } \\
(\mathrm{mTorr})\end{array}$ & $\begin{array}{c}\text { Power } \\
(\mathrm{W})\end{array}$ & $\begin{array}{c}\text { Bias potential } \\
(-\mathrm{V})\end{array}$ & $\begin{array}{c}\text { Etch rate } \\
(\mathrm{nm} / \mathrm{min})\end{array}$ & $\begin{array}{c}\text { RMS roughness } \\
(\mathrm{nm})\end{array}$ & $\begin{array}{c}\Gamma_{F} \\
\Gamma_{I+}\end{array}$ & $\begin{array}{c}\mathrm{n}_{e} \\
\left(10^{10} \mathrm{~cm}^{-3}\right)\end{array}$ & Condition \\
\hline 10 & 300 & 7 & 4 & $25.9 \pm 3.4$ & & & $\mathrm{C}_{1}$ \\
10 & 300 & 50 & 25 & $22.1 \pm 1.0$ & 178.3 & 0.4 & \\
10 & 300 & 100 & 34 & $17.3 \pm 0.5$ & & & $\mathrm{C}_{2}$ \\
10 & 300 & 150 & 65 & $19.5 \pm 0.4$ & & & $\mathrm{C}_{3}$ \\
\hline 3 & 1200 & 100 & 170 & $73.6 \pm 6.7$ & 149.9 & 4.5 & \\
6 & 1200 & 100 & 115 & $57.7 \pm 1.4$ & 175.6 & 2.5 & $\mathrm{C}_{5}$ \\
10 & 1200 & 100 & 94 & $10.4 \pm 1.0$ & 184.8 & 1.6 & \\
15 & 1200 & 100 & 67 & $27.1 \pm 1.8$ & 184.5 & 1.1 & $\mathrm{C}_{4}$ \\
20 & 1200 & 100 & 76 & $30.4 \pm 1.8$ & 180.5 & 0.8 & \\
\hline
\end{tabular}

$\mathrm{Sb}-\mathrm{F}$ bonds and eject the atoms from the surface, giving also a smoothing effect. The etch rate is closely related to the sputtering yields. Therefore, it is coherent to observe an increase of the etch rate with the bias potential.

Fig. 6 shows the simulation data as function of the chamber pressure. The high dissociation rate of $\mathrm{SF}_{6}$ (Fig. 6a) and the high electronic density (Table 1) lead to higher fluorine atom flux and fluorine ion flux (Fig. 6b), which are likely to react with the Ge-Sb-Se. Note there is discrepancy in literature concerning the variation of the fluorine atom density which must be discussed. Yang et et al. reported an increase of the fluorine atomic density [39], whereas Kokoris et al. observed a nonmonotonic variation [40]. Tinck et al. justified the drop of $\mathrm{SF}_{x}$ densities with the chamber pressure due to the recombination reactions within the plasma, while showing the $\mathrm{F}$ and $\mathrm{SF}_{6}$ densities increase [41]. Haidar et al. reported an increase of the fluorine flux with the decreasing 
pressure, in which the variation is thought to be related to the dissociation of $\mathrm{SF}_{6}$ [42]. The major difference between the different simulation studies is mainly due to the electronic density which can strongly increase with the decreasing pressure, or at the opposite, exhibits a low variation. In the former case, the fluorine atom flux is expected to increase with the dissociation degree of $\mathrm{SF}_{6}$, compensating the loss of $\mathrm{SF}_{6}$ total pressure, whereas in the latter case, the increasing feed gas pressure enhances the production of fluorine atom. As the pressure increases, the total positive ionic flux decreases faster than the fluorine atom flux, resulting in a slight increase of the $\frac{\Gamma_{F}}{\Gamma_{I+}}$ ratio (Table 1). Therefore, the etching of nonvolatile species is less effective and the etch rate drops with the working pressure.

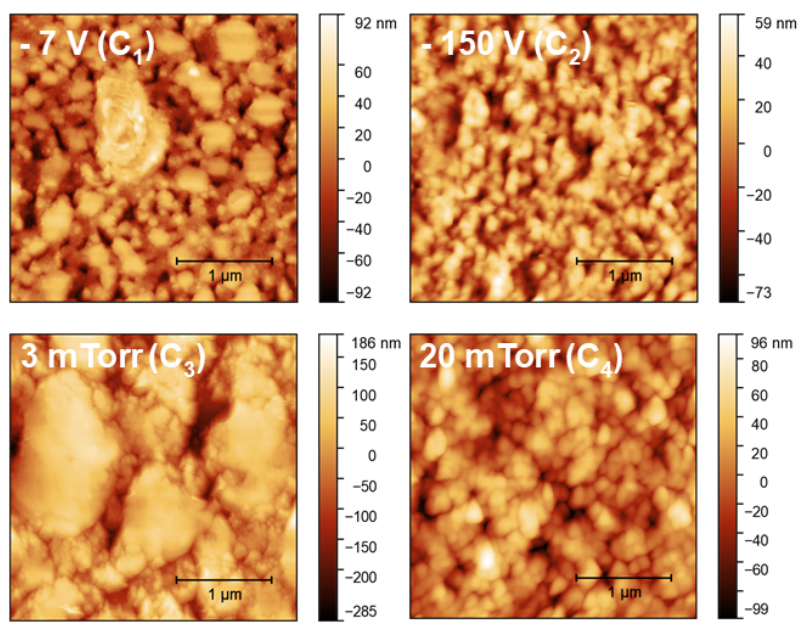

Fig. 7: AFM scans of etched Ge-Sb-Se thin films. Corresponding conditions are shown in Table 1.

Regardless of the conditions used in $\mathrm{SF}_{6}$ pure plasma, the surface can be assimilated as nanoislands as shown in Fig. 7. The extreme situations arise at lower pressure and lower bias potential with an important accumulation of nonvolatile species.

As can be seen in Fig. 8a, the etch rate is sharply reduced and the RMS roughness is increased until the nanostructured islands reach a maximum height (Fig. 8b), which is typical of a micromasking effect. The mechanism is known to arise from metal contamination (hardmask, wall) or nonvolatile etch products formation. Although an Al-F environment is detected with an unbiased substrate holder, the environment is undetected when applying a bias $\left(\mathrm{V}_{\text {bias }}<-50 \mathrm{~V}\right)$ to the substrate holder. In view of this information, the origin of the micromasking, discussed in Fig. 8 and further in this paper, is solely attributed to nonvolatile etch products. An etch rate of 

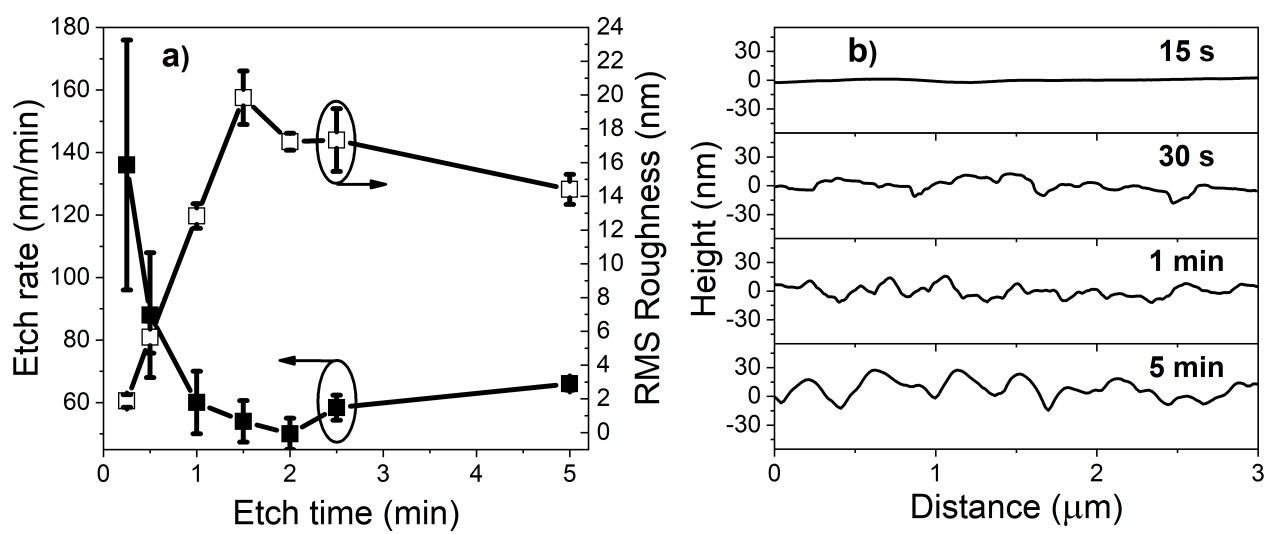

Fig. 8: a) Etch rate and RMS roughness; b) AFM trace after $\mathrm{SF}_{6}$ etching. (Etching conditions: 10 mTorr, 20 sccm, 700 $W$ and $-100 \mathrm{~V})$

approximately $3.5 \mu \mathrm{m} / \mathrm{min}$ has been reported for the etching of the Ge-Se related material in a $100 \% \mathrm{SF}_{6}$ plasma with an unbiased substrate, confirming that the $\left[\mathrm{GeSe}_{4 / 2}\right]$ motif is chemically etched [43]. At the surface of the Ge-Sb-Se thin film, most of the Ge atoms are chemically etched during the first minute, producing $\mathrm{GeF}_{2}$ and $\mathrm{GeF}_{4}$ volatile etch products, whereas the (Se)-Sb-F , $\mathrm{SbF}_{3}$ and $(\mathrm{Sb})-\mathrm{Se}-\mathrm{F}$ environments accumulate at the surface. During that short etching period, both chemical etching and physical etching are effective, resulting in a higher etch rate. As the surface becomes Ge-depleted, the process relies mainly on the ion sputtering of nonvolatile products, and the synergistic phenomenon between ion bombardment and chemical etching is significantly lessened, which leads to a stabilization of the etch rate.

A $100 \% \mathrm{SF}_{6}$ etching process is known to induce a chemical etching process. It is notably efficient for the elements of the $14^{\text {th }}$ column $(\mathrm{Si}, \mathrm{Ge})$ since the process forms volatile products $\left(\mathrm{SiF}_{4}, \mathrm{GeF}_{4}\right)$. However, the efficiency of a process is mostly affected by its limit. For the ternary material, we identify the constraint as the formation of $(\mathrm{Se})-\mathrm{Sb}-\mathrm{F}_{x}, \mathrm{SbF}_{3}$ and $(\mathrm{Sb})-\mathrm{Se}-\mathrm{F}$ entities.

Fig. 9 shows a SEM oblique image of a trench-patterned in the Ge-Sb-Se thin film, after the removal of the resist mask. Region (1) corresponds to the trench top, region (2) to the trench sidewall and region (3) to the trench bottom. As seen on the figure, the trench sidewall is very rough as compared to the trench bottom. Our interpretation is that this roughness results from the accumulation of nonvolatile etch products. Two main origins can be proposed: the deposition of non-volatile species coming from the etching of the trench bottom and the less efficient etching of the sidewall in relation to the weaker ion flux received. 


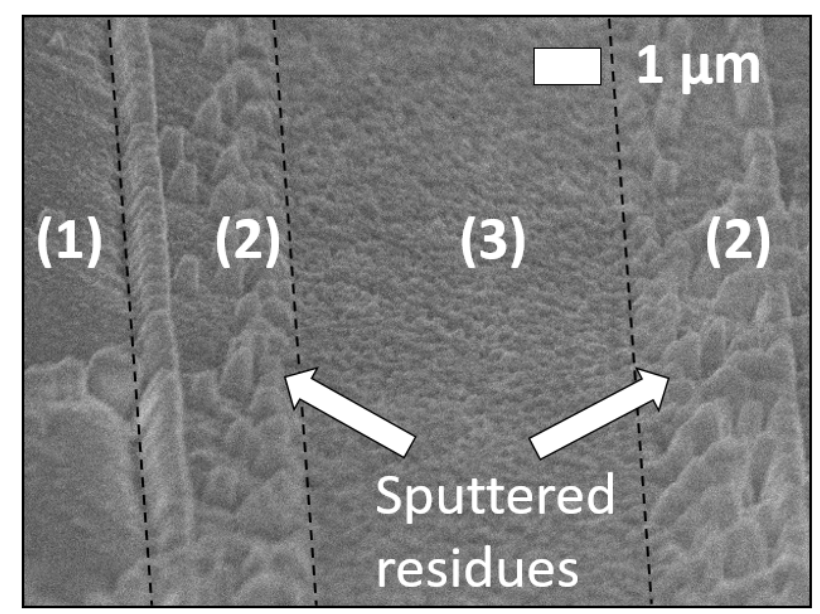

Fig. 9: Oblique view SEM images of a trench-patterned Ge-Sb-Se thin film after etching with a $\mathrm{SF}_{6}$ plasma at $10 \mathrm{mTorr}$, $1200 \mathrm{~W},-100 \mathrm{~V}$ and $20 \mathrm{sccm}$ (Condition $\mathrm{C}_{5}$ in Table 1 during 5 minutes). (1) Top (2) Sidewall (3) Bottom.

Thereafter, we propose to slow down the formation rate of the (Se)-Sb- $\mathrm{F}_{x}, \mathrm{SbF}_{3}$ and (Sb)Se-F entities by adding argon to $\mathrm{SF}_{6}$. The idea is to increase the ionic flux and to decrease the fluorine atom flux. The same approach was experimented on silica glass [44] and on the Ge-Sb-Te material [45].

\subsection{Etching in $S F_{6} / \mathrm{Ar}$}

\subsubsection{Effects of argon addition}

Plasma modeling data are displayed in Fig. 10a, Fig. 10b and Table 2. The increase of the electronic density (Table 2) with the argon percentage in the $\mathrm{SF}_{6} / \mathrm{Ar}$ mixture is consistent with the experimental data [20] and the literature [39, 46, 47]. As the plasma density increases, the dissociation of the precursor is enhanced as well as the ionization of reactive neutral species. It results in a slight decrease of the fluorine atom flux, and a near-constant variation of the $\mathrm{F}^{+}$and $\mathrm{SF}_{x}^{+}$fluxes. Above $40 \%$ of argon, the dominant contribution of the neutral flux is the fluorine atom flux with values one to three orders of magnitude higher than those of the $\mathrm{SF}_{x}$ radicals.

It was experienced that adding argon to fluorine-based plasmas increases the ionic flux for a high content of argon [26, 44, 48]. The same behaviour is observed with plasma modeling. For the investigated argon percentage ( 40 to $95 \%$ ), $\mathrm{Ar}^{+}$is the dominant contribution of the ionic flux. Even if the flux of $\mathrm{F}^{+}$is of the same order of magnitude, one must consider the sputtering yield which is higher for $\mathrm{Ar}^{+}$sputtering than $\mathrm{F}^{+}$sputtering. Between 80 to $95 \%$ of argon, a noticeable variation of the $\frac{\Gamma_{F}}{\Gamma_{A r^{+}}}$ratio (Table 2) provides a compelling evidence that the etching 
Table 2: Etch rate, RMS roughness and simulation data $\left(\Gamma_{F}\right.$ : fluorine atom flux; $\Gamma_{A r^{+}}$: argon ion flux; $\mathrm{n}_{e}$ : electronic density) according to plasma conditions with the source power set at $900 \mathrm{~W}$. The margin error of the etch rate is \pm 2 $\mathrm{nm} / \mathrm{min}$.

\begin{tabular}{ccccccc}
\hline $\begin{array}{c}\text { Ar percentage } \\
\text { (of total pressure) }\end{array}$ & $\begin{array}{c}\text { Pressure } \\
(\mathrm{mT} \text { Torr })\end{array}$ & $\begin{array}{c}\text { Bias potential } \\
(-\mathrm{V})\end{array}$ & $\begin{array}{c}\text { Etch rate } \\
(\mathrm{nm} / \mathrm{min})\end{array}$ & $\begin{array}{c}\text { RMS roughness } \\
(\mathrm{nm})\end{array}$ & $\begin{array}{c}\Gamma_{F} \\
\Gamma_{A r^{+}}\end{array}$ & $\begin{array}{c}\mathrm{n}_{e} \\
\left(10^{11} \mathrm{~cm}^{-3}\right)\end{array}$ \\
\hline 95 & 2 & 150 & 53 & $1.4 \pm 0.1$ & 7.1 & 7.76 \\
90 & 2 & 150 & 89 & $1.5 \pm 0.1$ & 30.0 & 9.17 \\
80 & 2 & 150 & 197 & $7.2 \pm 0.2$ & 93.5 & 8.14 \\
$\mathbf{6 0}$ & $\mathbf{2}$ & $\mathbf{1 5 0}$ & $\mathbf{4 6 7}$ & $\mathbf{3 0 . 5} \pm \mathbf{4 . 0}$ & $\mathbf{4 4 1 . 8}$ & $\mathbf{4 . 1 1}$ \\
40 & 2 & 150 & 203 & $8.5 \pm 0.6$ & 1050.5 & 2.58 \\
\hline 95 & 0.5 & 200 & 78 & $0.9 \pm 0.1$ & & \\
95 & 1 & 200 & 94 & $0.9 \pm 0.1$ & 2.4 & 5.97 \\
95 & 2 & 200 & 94 & $1.4 \pm 0.2$ & 7.1 & 7.76 \\
95 & $\mathbf{4}$ & $\mathbf{2 0 0}$ & $\mathbf{1 2 9}$ & $\mathbf{4 . 6} \pm \mathbf{0 . 2}$ & $\mathbf{1 9 . 3}$ & $\mathbf{1 0 . 4}$ \\
95 & 10 & 200 & 68 & $4 \pm 0.1$ & 61.2 & 5.12 \\
95 & 16 & 200 & 63 & $6.6 \pm 0.7$ & 82.3 & 2.24 \\
\hline
\end{tabular}
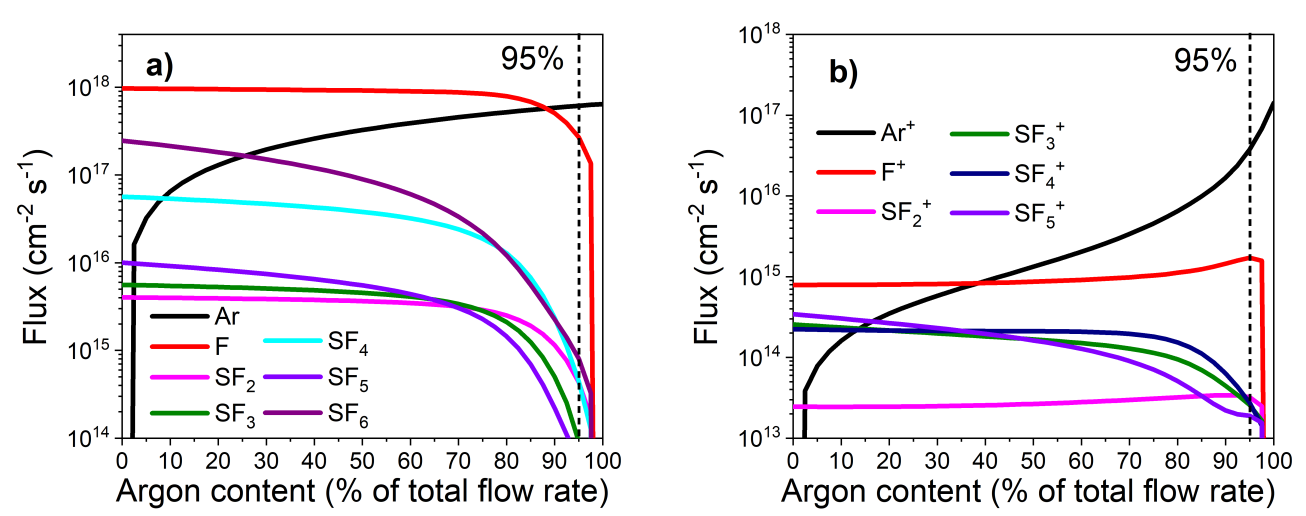

Fig. 10: a) Radical fluxes and b) positive ion fluxes according to argon content at $900 \mathrm{~W}, 2$ mTorr and $40 \mathrm{sccm}$ (modeling).

moves towards an important ion bombardment regime.

Fig. 11a presents the area ratios calculated from decomposed Sb 3d and Se 3d XPS spectra; Fig. $11 \mathrm{~b}$ shows the relative atomic proportion of $\mathrm{Ge}, \mathrm{Sb}$ and $\mathrm{Se}$; and the relative area of the $\mathrm{F}$ 1s region; and Table 2 lists the etch rate and roughness according to the Ar percentage in the $\mathrm{SF}_{6} / \mathrm{Ar}$ mixture. Drastic change of surface composition are evidenced with the reduction of the fluorinated species compared with the related selenide species. The analysis of the $G e 2 p_{3 / 2}$ is not reliable because of the overlapping between the $(\mathrm{Se})-\mathrm{Ge}-\mathrm{F}_{x}$ species and the $\left[\mathrm{GeSe}_{4 / 2}\right]$ motif.

At $40 \%$ of argon, the F 1s is the dominant contribution among the investigated core levels (70.9\% of total area). It should be reminded that the high content of fluorine is essentially 

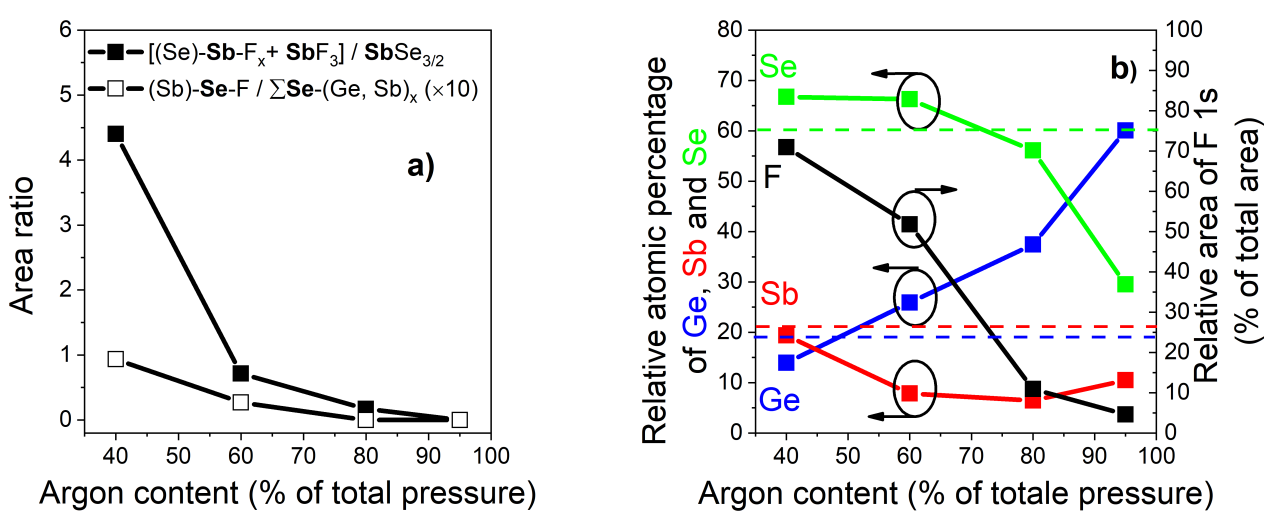

Fig. 11: a) Area ratio b) $\mathrm{Ge}, \mathrm{Sb}$ and Se relative atomic percentages and $\mathrm{F}$ 1s relative area as a function of the argon percentage in the gas mixture. The dash lines correspond to the atomic percentages of Ge, Sb and Se of the nonetched Ge-Sb-Se thin film. Corresponding conditions are shown in Table 2.

due to the Sb-F bonding, which is responsible of the micromasking effect. As can be seen in Table 2, we note a nonmonotonic variation of the etch rate at $60 \%$ of argon, resulting of a synergistic effect because of the increasing Ar ion flux (see Fig. 10b). As evidenced in Fig. $11 \mathrm{a}$, there is a noticeable drop of the relative area of the fluorinated environments $\left(\mathrm{Sb}-\mathrm{F}_{x}\right.$ and Se-F) from 40 to $60 \%$ of argon. With the increasing Ar ion flux, the removal rate of nonvolatile species such as $(\mathrm{Se})-\mathrm{Sb}-\mathrm{F}_{x}$ and $\mathrm{SbF}_{3}$ is increased, leading to an increase of the $\mathrm{Sb}-\mathrm{Se}$ bonds at the surface. Concerning the $\mathrm{Sb} 3 \mathrm{~d}$ core level, the $\left[\mathrm{SbSe}_{3 / 2}\right]$ motif is dominant at $60 \%$ of argon, and the sputtering of atoms ( $\mathrm{Sb}$ and $\mathrm{Se}$ ) is likely to be enhanced with the increasing ionic flux. Nevertheless, it is worth noting that the relative area of fluorinated species remains significant. In that regard, the surface contains two distinct chemical bonds for $\mathrm{Sb}$ atoms: $\mathrm{Sb}-\mathrm{F}$ and $\mathrm{Sb}-\mathrm{Se}$. As the bond energy for $\mathrm{SbF}_{3}$ is higher (440 kJ/mol) [49] than that of the pyramidal [ $\mathrm{SbSe}_{3 / 2}$ ] (179 to $184 \mathrm{~kJ} / \mathrm{mol}$ ) [50-52], it is expected that both species reacts differently to the increasing ion bombardment. Such disparity could be responsible of the higher RMS roughness $(30.5 \mathrm{~nm})$. At $80 \%$ of argon, the surface contains less fluorine ( $10.9 \%$ of total area) and is Ge-enriched. Since the quantification is performed using the $\mathrm{Ge} 2 \mathrm{p}_{3 / 2}$ core level and not the Ge $3 \mathrm{~d}$ core level, the Ge relative percentage is overestimated, and so, $\mathrm{Se}$ and $\mathrm{Sb}$ relative percentages are underestimated. At $95 \%$ of argon, $\mathrm{SbF}_{3},(\mathrm{Se})-\mathrm{Sb}-\mathrm{F}_{x}$ and $(\mathrm{Sb})-\mathrm{Se}-\mathrm{F}$ environments are undetected (at. $\left.<1 \%\right)$. Simultaneously, the AFM measurement presents the lowest value of RMS roughness (1.4 nm) and the lowest etch rate $(53 \mathrm{~nm} / \mathrm{min})$, meaning that the rate limiting step of the $\mathrm{SF}_{6} / \mathrm{Ar}(5 \% / 95 \%)$ etching is the fluorine atom flux. 


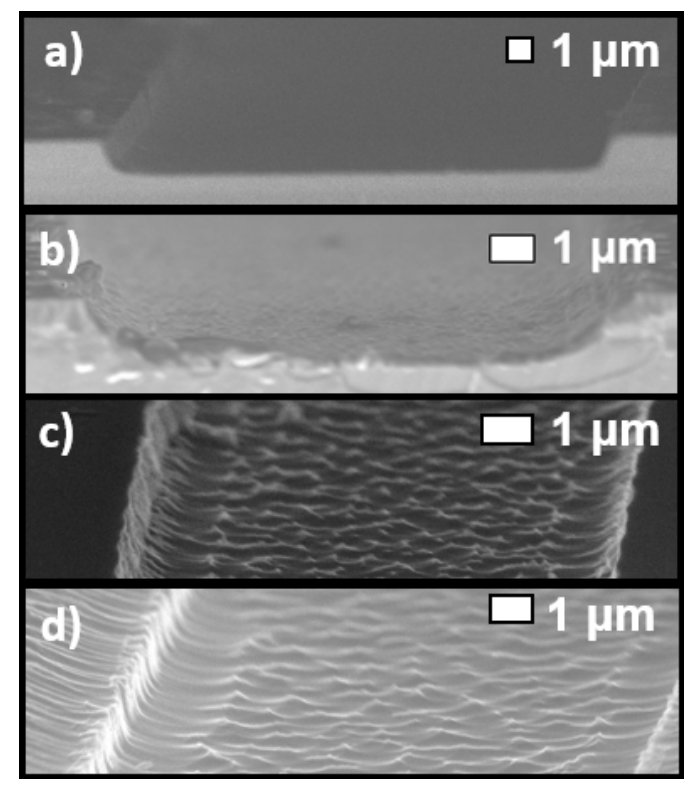

Fig. 12: SEM images of trench-patterned of Ge-Sb-Se thin films after etching with $\mathrm{SF}_{6} / \mathrm{Ar}$ at a) $95 \%$ Ar (etch time: 23 min) b) $80 \% \mathrm{Ar}$ (etch time: $6 \mathrm{~min}$ ) c) 60\% Ar (etch time: 2 min 30) and d) 40\% Ar (etch time: 6 min). Corresponding conditions are shown in Table 2.

Impact of varying the plasma mixture on pattern etching was also investigated. SEM images of the Ge-Sb-Se patterned samples (etch depth $\sim 1.2 \mu \mathrm{m}$ ) are shown in Fig. 12. As can be seen at $95 \%$ of argon in Fig. 12a, there is a very smooth surface with a quasi-vertical profile. It is also the condition where the fluorine atom concentration is the lowest whether it is in the plasma or at the surface. At $80 \%$ of argon (Fig. 12b), the patterned Ge-Sb-Se contains some residues on the surface and a large sidewall angle. At argon percentage lower than $60 \%$ of total pressure (Fig. 12c and Fig. 12d), the micromasking effect is apparent and it is related to the important concentration of nonvolatile species at the surface. It seems that there is a strong coherence with blank (Table 2) and patterned samples regarding the roughness.

\subsubsection{Effects of pressure}

Along with the argon content and the bias, the pressure is usually a key parameter to optimize an etching process. Through the variation of pressure, the plasma chemistry can be modified drastically. In this section, we investigate the etching of the Ge-Sb-Se thin films using a gas mixing ratio $\mathrm{SF}_{6} / \mathrm{Ar}=5 / 95$.

Plasma modeling data are presented in Fig. 13 and Table 2. Total radical fluxes and total ionic 


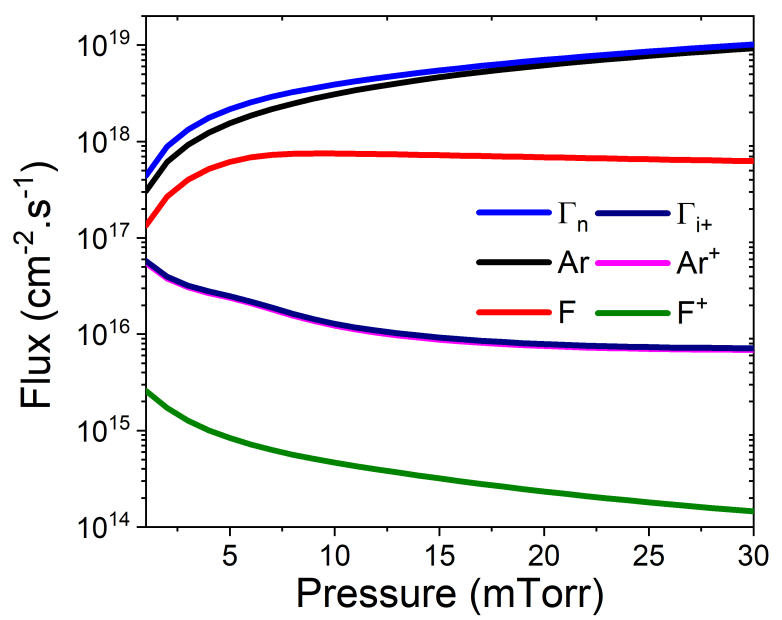

Fig. 13: Fluxes according to the pressure at $900 \mathrm{~W}, 95 \%$ of $\mathrm{Ar}$ and $40 \mathrm{sccm}$ (modeling). ( $\Gamma_{n}$ : total radical flux; $\Gamma_{i+}$ : total ionic flux)

flux could be roughly interpreted with the fluorine atom flux and the argon ion flux as evidenced in Fig. 10a and Fig. 10b. Yang et al. reported a nonmonotonic variation of the electronic density, for $\mathrm{Ar}$ content greater than 30\%, attributed to the competition between the ionization processes (i.e. electron production) and the dissociative attachment (i.e. electron loss) [39]. It should be noticed that the mass-balance equation takes into account the loss rates of neutral species to the wall due to the diffusion [20]. The gain of fluorine through dissociation of $\mathrm{SF}_{6}$ is sharply offset by the surface loss at lower pressure. Therefore, the fluorine atom flux drops as going from 8 to 1 mTorr. As the pressure decreases, the energy to produce a positive ion is reduced because of the high dissociation rate of the $\mathrm{SF}_{x}$ fragments. It accentuates the ionization processes at lower pressure.

The area ratios extracted from Sb 3d and Se 3d XPS spectra are plotted in Fig. 14a. The relative area of F 1s and the relative atomic percentages are displayed in Fig. 14b. At 2 mTorr, the formation rate of the fluorinated species is offset by the significant ion bombardment (Fig. 13). In other terms, the newly formed Sb-F bonds are constantly broken, leading to a very smooth surface from 0.5 to 2 mTorr with RMS roughness values between 0.9 and $1.4 \mathrm{~nm}$ (Table 2). Beyond 2 mTorr, the argon ion flux drops and the chemical etching of Ge become efficient. In addition, the $\mathrm{SbF}_{3}$ and $(\mathrm{Se})-\mathrm{Sb}-\mathrm{F}_{x}$ species are detected at the surface and, as mentionned in Sec 3.2.1, the disparity between the Sb-Se and Sb-F bond energy may accentuate the RMS 
roughness. It is worth noting that there is a synergistic effect between the etching agent and the ion bombardment at $4 \mathrm{mTorr}(129 \mathrm{~nm} / \mathrm{min})$, despite the accumulation of nonvolatile species. Furthermore, the ( $\mathrm{Sb}$ )-Se-F environment is only detected at $8 \mathrm{mTorr}$. A higher fluorine atom flux in the plasma leads to an important concentration of fluorine at the surface (60.9\% of total area), but also a Se-enrichment (considering $\mathrm{Ge}, \mathrm{Sb}$ and $\mathrm{Se}$ )
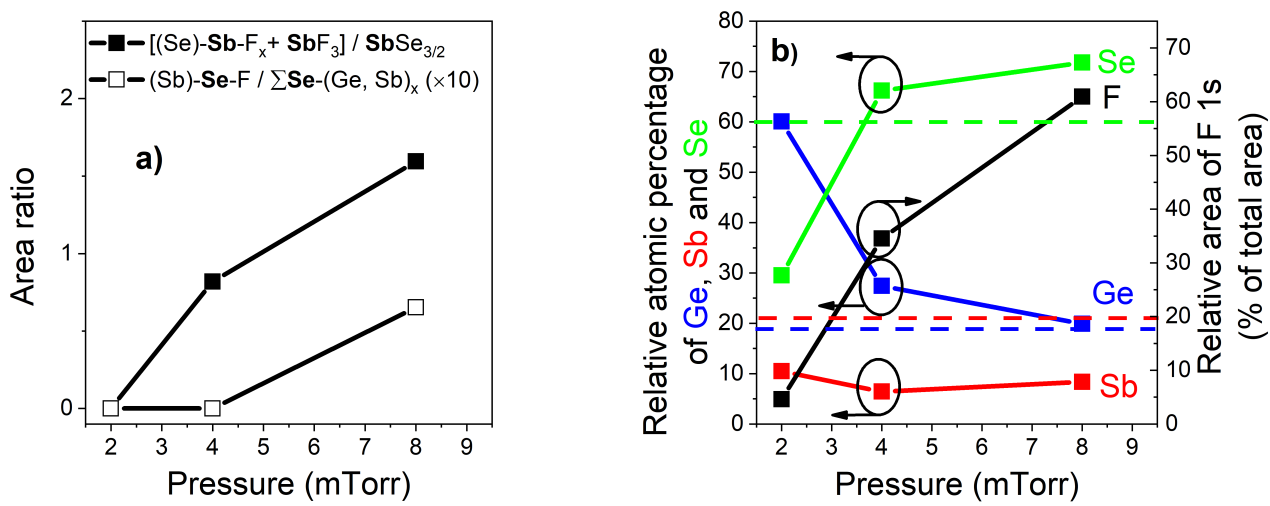

Fig. 14: a) Area ratio b) $\mathrm{Ge}, \mathrm{Sb}$ and Se relative atomic percentages and $\mathrm{F}$ 1s relative area as a function of the pressure.The dash lines correspond to the atomic percentages of $\mathrm{Ge}$, Sb and Se of the nonetched Ge-Sb-Se thin film. Corresponding conditions are shown in Table 2 with a bias set at $-150 \mathrm{~V}$.

Fig. 15 shows the SEM images of etched profiles for low and high $\frac{\Gamma_{F}}{\Gamma_{A r^{+}}}$conditions (see Fig. 13 and Table 2). As can been seen in Fig. 15a and Fig. 15b, the lower pressure case (1.5 mTorr) exhibits a very smooth surface and a quasi-vertical profile. The condition at 16 mTorr (Fig. $15 \mathrm{c}$ and Fig. 15d) suggests, as with a $100 \% \mathrm{SF}_{6}$ etching, that the nonvolatile species induces a micromasking effect and a tapered profile due to a redeposit on the sidewall.

\section{Conclusion}

$\mathrm{Ge}-\mathrm{Sb}$-Se thin films were studied in pure a $\mathrm{SF}_{6}$ plasma. We identified the origin of roughness as the formation of $\mathrm{SbF}_{3},(\mathrm{Se})-\mathrm{Sb}-\mathrm{F}_{x}$ and $(\mathrm{Sb})-\mathrm{Se}-\mathrm{F}$ environments. We presented a way to reduce the formation rate of the nonvolatile products by adding argon to $\mathrm{SF}_{6}$ plasma. XPS analyses showed explicitly that the Sb-F or Se-F bonds were not detected for a high argon percentage (95\%) and for low-pressure processes $(<4$ mTorr). The surface composition and the etching profile were improved by adding argon, despite the fact that the etch rate decreases with argon content. By optimizing the argon content and the pressure, it was possible to obtain a very 


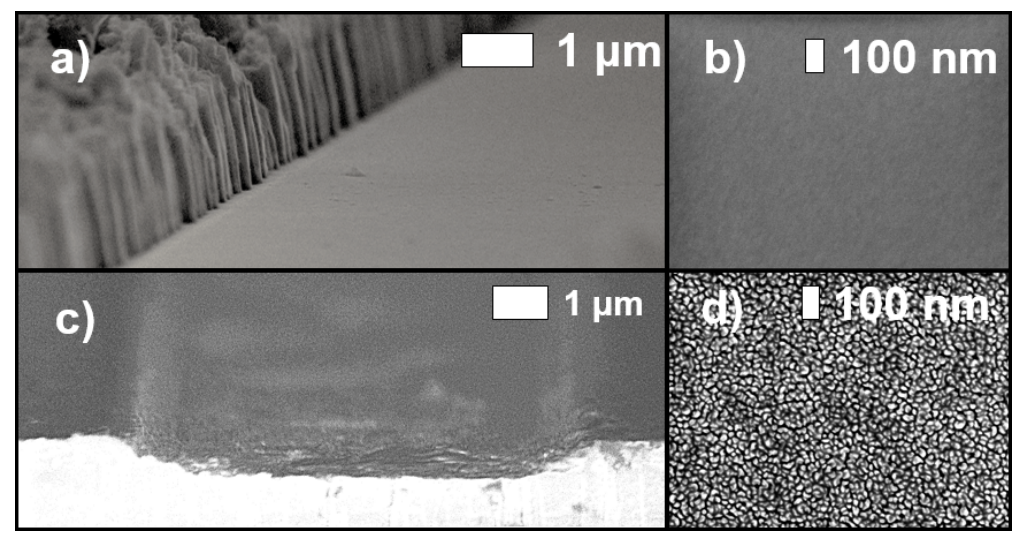

Fig. 15: SEM images of patterned trench of Ge-Sb-Se thin films and blank Ge-Sb-Se thin films after dry etching with $\mathrm{SF}_{6} / \mathrm{Ar}(5 \% / 95 \%)$ at $900 \mathrm{~W},-200 \mathrm{~V}, 40.5 \mathrm{sccm}$ at a) $1.5 \mathrm{mTorr}$ (oblique view; etch time: $20 \mathrm{~min}$ ) b) $1.5 \mathrm{mTorr}$ (top view; etch time: $5 \mathrm{~min}$ ) c) 16 mTorr (oblique view; etch time: $20 \mathrm{~min}$ ) d) 16 mTorr (top view; etch time: $5 \mathrm{~min}$ ).

smooth surface and a vertical profile. These are promising results for the $\mathrm{SF}_{6} / \mathrm{Ar}$ mixture. Further optimizations should be focused to improve the sidewall roughness.

It should be pointed out that this study is of interest for the etching of antimony-based materials using fluorine-based plasmas at ambient temperature.

\section{Acknowledgements}

Czech Science Foundation (project no. 19-24516S) and the Barrande exchange program between France and the Czech Republic are greatly acknowledged for supporting this work.

\section{References}

[1] J.-L. Adam, X. Zhang, Chalcogenide Glasses: Preparation, Properties and Applications, Woodhead Publishing, 2014.

[2] S. J. Madden, D.-Y. Choi, D. A. Bulla, A. V. Rode, B. Luther-Davies, V. G. Ta'eed, M. D. Pelusi, B. J. Eggleton, Opt. Express 15 (2007) 14414-14421.

[3] V. Nazabal, F. Charpentier, J.-L. Adam, P. Němec, H. Lhermite, M.-L. Brandily-Anne, J. Charrier, J.-P. Guin, A. Moréac, Int. J. Appl. Ceram. Technol. 8 (2010) 990-1000.

[4] J. Charrier, M.-L. Brandily, H. Lhermite, K. Michel, B. Bureau, F. Verger, V. Nazabal, Sens. Actuator B-Chem. 173 (2012) 468-476.

[5] D. Y. Choi, S. Madden, A. Rode, R. Wang, B. Luther-Davies, Appl. Phys. Lett. 91 (2007) 011115.

[6] A. Ganjoo, H. Jain, C. Yu, R. Song, J. V. Ryan, J. Irudayaraj, Y. J. Ding, C. G. Pantano, J. Non-Cryst. Solids 352 (2006) 584-588.

[7] M.-L. Anne, J. Keirsse, V. Nazabal, K. Hyodo, S. Inoue, C. Boussard-Pledel, H. Lhermite, J. Charrier, K. Yanakata, O. Loreal, J. Le Person, F. Colas, C. Compère, B. Bureau, Sensors 9 (2009) 7398-7411.

[8] F. Verger, V. Nazabal, F. Colas, P. Němec, C. Cardinaud, E. Baudet, R. Chahal, E. Rinnert, K. Boukerma, I. Peron, S. Deputier, M. Guilloux-Viry, J. P. Guin, H. Lhermite, A. Moreac, C. Compère, B. Bureau, Opt. Mater. Express 3 (2013) 2112-2131.

[9] P. K. Tien, Appl. Opt. 10 (1971) 2395-2413.

[10] V. Balan, C. Vigreux, A. Pradel, A. Llobera, C. Dominguez, M. I. Alonso, M. Garriga, J. Non-Cryst. Solids 326-327 (2003) 455-459. 
[11] W. Li, Y. Ruan, B. Luther-Davies, A. Rode, R. Boswell, J. Vac. Sci. Technol. A 23 (2005) 1626-1632.

[12] J. Charrier, M. L. Anne, H. Lhermite, V. Nazabal, J. P. Guin, F. Charpentier, T. Jouan, F. Henrio, D. Bosc, J. Adam, J. Appl. Phys. 104 (2008) 073110.

[13] Q. Du, Y. Huang, J. Li, D. Kita, J. Michon, H. Lin, L. Li, S. Novak, K. Richardson, W. Zhang, J. Hu, Opt. Lett. 41 (2016) 3090-3093.

[14] J. Li, X. Shen, J. Sun, K. Vu, D.-Y. Choi, R. Wang, B. Luther-Davies, S. Dai, T. Xu, Q. Nie, Thin Solid Films 545 (2013) 462-465.

[15] W. Zhang, S. Dai, X. Shen, Y. Chen, S. Zhao, C. Lin, L. Zhang, J. Bai, Mater. Lett. 98 (2013) $42-46$.

[16] E. Baudet, A. Gutierrez-Arroyo, P. Němec, L. Bodiou, J. Lemaitre, O. D. Sagazan, H. Lhermitte, E. Rinnert, K. Michel, B. Bureau, J. Charrier, V. Nazabal, Opt. Mater. Express 6 (2016) 2616-2627.

[17] H. Xiong, Y. Shi, Z. Wang, Microelectron. Eng. 225 (2020) 111259.

[18] E. Baudet, C. Cardinaud, R. Boidin, A. Girard, J. Gutwirth, P. Němec, V. Nazabal, J. Am. Ceram. Soc. 101 (2018) 3347-3356.

[19] D. A. Shirley, Phys. Rev. B 5 (1972) 4709-4714.

[20] L. Lallement, A. Rhallabi, C. Cardinaud, M. C. Peignon-Fernandez, L. L. Alves, Plasma Sources Sci. Technol. 18 (2009) 025001

[21] C. Lee, M. A. Lieberman, J. Vac. Sci. Technol. A 13 (1995) 368-380.

[22] V. Tarnovsky, H. Deutsch, K. E. Martus, K. Becker, J. Chem. Phys. 109 (1998) 6596-6600.

[23] C. Riccardi, R. Barni, F. d. Colle, M. Fontanesi, IEEE Trans. Plasma Sci. 28 (2000) 278-287.

[24] L. G. Christophorou, J. K. Olthoff, J. Phys. Chem. Ref. Data 29 (2000) 267-330.

[25] K. R. Ryan, I. C. Plumb, Plasma Chem. Plasma Process. 10 (1990) 207-229.

[26] S. Rauf, P. L. G. Ventzek, I. C. Abraham, G. A. Hebner, J. R. Woodworth, J. Appl. Phys. 92 (2002) 6998-7007.

[27] P. J. Chantry, J. Appl. Phys. 62 (1987) 1141-1148.

[28] C. C. Addison, Inorganic Chemistry of the Main-Group Elements, volume 2, Royal Society of Chemistry, 1974.

[29] K. D. Abney, G. R. Ball, P. G. Eller, J. Fluor. Chem. 51 (1991) 165-170.

[30] C. L. Yaws, M. A. Satyro, in: The Yaws Handbook of Vapor Pressure (Second Edition), Gulf Professional Publishing, 2015, pp. 315-322.

[31] W.-H. Wei, S. Xiang, S.-W. Xu, L. Fang, R.-P. Wang, J. Appl. Phys. 115 (2014) 183506.

[32] E. Baudet, C. Cardinaud, A. Girard, E. Rinnert, K. Michel, B. Bureau, V. Nazabal, J. Non-Cryst. Solids 444 (2016) 64-72.

[33] W. E. Morgan, W. J. Stec, J. R. Van Wazer, Inorg. Chem. 12 (1973) 953-955.

[34] T. Birchall, J. A. Connor, L. H. Hillier, J. Chem. Soc., Dalton Trans. (1975) 2003-2006.

[35] C. D. Wagner, Faraday Discuss. Chem. Soc. 60 (1975) 291-300.

[36] A. H. Goldan, C. Li, S. J. Pennycook, J. Schneider, A. Blom, W. Zhao, J. Appl. Phys. 120 (2016) 135101.

[37] D. Hohl, R. O. Jones, R. Car, M. Parrinello, Chem. Phys. Lett 139 (1987) 540-545.

[38] D. C. Sati, A. Kovalskiy, R. Golovchak, H. Jain, J. Non-Cryst. Solids 358 (2012) 163-167.

[39] W. Yang, S.-X. Zhao, D.-Q. Wen, W. Liu, Y.-X. Liu, X.-C. Li, Y.-N. Wang, J. Vac. Sci. Technol. A 34 (2016) 031305 .

[40] G. Kokkoris, A. Panagiotopoulos, A. Goodyear, M. Cooke, E. Gogolides, J. Phys. D: Appl. Phys. 42 (2009) 055209

[41] S. Tinck, T. Tillocher, R. Dussart, A. Bogaerts, J. Phys. D: Appl. Phys. 48 (2015) 155204.

[42] Y. Haidar, A. Pateau, A. Rhallabi, M. C. Fernandez, A. Mokrani, F. Taher, F. Roqueta, M. Boufnichel, Plasma Sources Sci. Technol. 23 (2014) 065037.

[43] T. Meyer, G. LeDain, A. Girard, A. Rhallabi, M. Bouška, P. Němec, V. Nazabal, C. Cardinaud, Plasma Sources Sci. Technol. 29 (2020) 105006.

[44] L. Lallement, C. Gosse, C. Cardinaud, M.-C. Peignon-Fernandez, A. Rhallabi, J. Vac. Sci. Technol. A 28 (2010) 277-286.

[45] G. Feng, B. Liu, Z. Song, S. Feng, B. Chen, Microelectron. Eng. 85 (2008) 1699-1704.

[46] G. A. Hebner, I. C. Abraham, J. R. Woodworth, Characterization of SF6/Argon Plasmas for Microelectronics Applications, Technical Report SAND2002-0340, Sandia National Labs., Albuquerque, NM (US); Sandia National Labs., Livermore, CA (US), 2002.

[47] S.-J. Oh, H.-C. Lee, C.-W. Chung, Phys. Plasmas 24 (2017) 013512.

[48] B. Mahi, J. Vac. Sci. Technol. B 5 (1987) 657.

[49] R. B. King, Encyclopedia of inorganic chemistry, Wiley, Chichester, West Sussex, England; Hoboken, NJ, 2006. OCLC: 60348994.

[50] A. Dahshan, K. Aly, Philos Mag 88 (2008) 361-372.

[51] S. Sharda, N. Sharma, P. Sharma, V. Sharma, Defect Diffus. Forum 316-317 (2011) 45-53.

[52] J. H. Lee, W. H. Lee, J. K. Park, J. H. Yi, S. Y. Shin, B. J. Park, B. So, J. Heo, J. H. Choi, H. J. Kim, Y. G. Choi, J. Non-Cryst. Solids 431 (2016) 41-46. 